\title{
Inhibition of growth of Anabaena variabilis population by single and mixed steroid hormones
}

\author{
Karolina Czarny ${ }^{1}$ (D) Dominik Szczukocki ${ }^{1}$ - Barbara Krawczyk ${ }^{1}$. Sławomira Skrzypek ${ }^{1}$ Ewa Miękoś ${ }^{1}$. \\ Renata Gadzała-Kopciuch ${ }^{2}$
}

Received: 27 March 2018 /Revised and accepted: 16 July 2018 /Published online: 7 August 2018

(C) The Author(s) 2018

\begin{abstract}
Many contaminants which are toxic and adversely affect living organisms enter surface waters. Among them, there are endocrine compounds such as steroid hormones, which can disrupt the endocrine system causing an adverse effect on the physiology of aquatic organisms. In the literature, there is not enough information about the influence of steroid hormones on phytoplankton growth. Therefore, the aim of this research was to study the effect of estrogens (estrone, 17ß-estadiol, 17- $\alpha$-ethinylestradiol, and estriol), progestagens (progesterone, 5-pregnen-3b-ol-20-one, and levonorgestrel), and androgens (testosterone) on the growth of the cyanobacterium Anabaena variabilis. To our best knowledge, the chronic toxicological effects of hormones on cyanobacteria are explored for the first time. From among single steroid hormones, progesterone and 17- $\alpha$-ethinylestradiol are the most toxic $\left(\mathrm{EC}_{50} 48.59\right.$ and $\left.82.95 \mathrm{mg} \mathrm{L}^{-1}\right)$. On the other hand, incubation in the presence of 5-pregnen-3b-ol-20-one, testosterone, and 17ßestadiol caused slight inhibition of growth $\left(\mathrm{EC}_{50} 283.50,336.68\right.$, and $\left.437.82 \mathrm{mg} \mathrm{L}^{-1}\right)$, while estrone, estriol, and levonorgestrel showed no significant effect on the growth of this cyanobacterium. Hormone mixtures have been found to be more toxic than single substances and exposure to them leads to the potentiation of toxicity. The $\mathrm{EC}_{50}$ after 14 days of the test duration for the mixed steroid hormones were $45.14,37.00$, and $89.46 \mathrm{mg} \mathrm{L}^{-1}$. This research provides a basic understanding of hormone toxicity to aquatic organism, such as cyanobacteria, and asserts a more comprehensive view on ecological risk evaluation.
\end{abstract}

Keywords Anabaena variabilis $\cdot$ Cyanobacteria $\cdot$ Phytoplankton $\cdot$ Hormones $\cdot$ Endocrine-disrupting compounds $\cdot$ Growth inhibition

\section{Introduction}

One of the most important ecological problems faced by humanity is the deepening pollution of the aquatic environment with both natural and industrial chemical compounds (Martinez-Alcala et al. 2018). Thousands of substances are widely used by humans, but only some of them have gone

Electronic supplementary material The online version of this article (https://doi.org/10.1007/s10811-018-1589-9) contains supplementary material, which is available to authorized users.

Karolina Czarny

karolina.czarny@chemia.uni.lodz.pl

1 Faculty of Chemistry, Department of Inorganic and Analytical Chemistry, Laboratory of Environmental Threats, University of Lodz, Tamka 12, 91-403 Lodz, Poland

2 Faculty of Chemistry, Department of Environmental Chemistry and Bioanalytics, Nicolaus Copernicus University, Gagarina 7, 87-100 Torun, Poland through toxicological evaluation (Dionisio et al. 2015). The Toxic Substances Control Act (TSCA) specifies over 85,000 chemical substances, of which about $1 \%$ are endocrine disruptor chemicals (EDCs) that interfere with the hormonal balance of organisms and cause harmful changes in the reproductive, nervous, and immune systems (Erickson 2017; DeWitt and Patisaul 2018). According to the American Environmental Protection Agency (EPA), EDCs are defined as exogenous substances that disrupt the metabolism of living organisms as well as the synthesis, secretion, metabolism, and transport of natural hormones and are responsible for disrupting homeostasis, reproduction, and changes in behavior (DiamantiKandarakis et al. 2009). Studies performed over the past two decades have shown that permanent exposure to low concentrations of EDCs leads to serious disturbances in the functioning of the endocrine system and their presence in surface waters can adversely affect the health of both humans and animals living in aquatic ecosystems (He et al. 2018; Nadal et al. 2018). The main groups of compounds 
include endocrine-disrupting compounds such as phytoestrogens (Patisaul and Jefferson 2010), polychlorinated biphenyls ( $\mathrm{Li}$ et al. 2016), polycyclic aromatic hydrocarbons (PAH) (Zhang et al. 2016), pesticides (Kida et al. 2018), dioxins (Brulport et al. 2017), phthalates and plastic ingredients (Dong et al. 2018), and natural and synthetic hormones (Ben Fredj et al. 2017). These substances are found in wastewater treatment plants and in the natural environment in rivers, lakes, and even oceans (do Nascimento et al. 2018). The ubiquitous occurrence of these chemical compounds in the aquatic environment is related to their persistence, ability to accumulate in organisms and sediments, low efficiency of wastewater treatment, and increased production (Daughton and Ternes 1999; Kabzinski et al. 2007; Macioszek et al. 2010; Aris et al. 2014; Zhang et al. 2017).

Recently, the number of reports on negative effects of hormones in the aquatic environment, as well as their negative impact on human and animal health, has increased (Ying et al. 2002; Czarny et al. 2017). For this reason, it is necessary to study the impact of these compounds on organisms living in aquatic ecosystems. Natural hormones excreted by humans and animals in the urine and their amounts are determined by gender, stage of growth, phase of the menstrual cycle and pregnancy (Wang and Zhu 2017). Synthetic hormones are used in hormonal and contraceptive drugs. These compounds get into surface waters with surface runoff from fields where natural fertilizers were used, and municipal wastewater and sewage from pharmaceutical plants where hormone-based drugs are produced (Hanselman et al. 2003; Leet et al. 2011). The growing concentration of synthetic hormones in the environment is associated not only with the increasingly popular contraception and hormonal drugs used by people, but also substances used to improve breeding performance and treatment of animals. Many publications have shown that hormones are toxic to aquatic organisms. Lei et al. (2013) demonstrated that exposure to $5 \mathrm{ng} \mathrm{L}^{-1}$ concentrations of estrone may cause irreversible gonadal damage to Japanese Medaka (Oryzias latipes) males and also lead to the complete feminization of their population. Phuge and Gramapurohit (2015) showed that exposure of frog, Xenopus tropicalis, larvae to $10 \mu \mathrm{g} \mathrm{L}^{-1}$ of $17 \beta$-estradiol leads to the complete feminization of males. Volkova and Goltsev (2015) showed that $17-\alpha$-ethinylestradiol induced behavioral changes of the guppy Poecilia reticulata at concentration $20 \mathrm{ng} \mathrm{L}^{-1}$. During exposure to $10 \mathrm{ng} \mathrm{L}^{-1}$ progesterone, an inhibition of reproductive processes and decrease in the amount of sperm in Pimephales promelas males were observed (DeQuattro et al. 2012). In contrast, the exposure of Danio rerio fish to this progestagen causes irreversible endocrine changes and leads to a change in gene expression (Liang et al. 2015; Sangster et al. 2016). The presence of testosterone in the aqueous environment reduces the concentration of vitellogenin in Gobiocypris rarus females, while in males of the same species, a significant decrease in sperm count compared to the control group was observed (Gao et al. 2015). Not only fish but also amphibians and reptiles are sensitive to testosterone in the aquatic environment. Piprek et al. (2012) carried out research on two species of frogs Bombina bombina and Bombina variegata, during which they showed that this hormone causes differentiation of gonads and promotes the creation of intersex individuals.

The assessment of the impact of pollution on aquatic ecosystems is an extremely difficult task due to the different sensitivity of aquatic organisms to chemical compounds present in the environment, and due to bioaccumulation in the upper links of the trophic chain, it is difficult to determine the longterm effects of their presence in water (Torres et al. 2008; Ahmed et al. 2018). In addition, in the natural environment organisms are often exposed to a complex mixture of pollutants and sometimes exposure to many compounds can cause interactions leading to a significant increase or decrease in the overall toxicity of the mixture compared to the sum of toxicities of individual components (Krishnan and Brodeur 1994). Therefore, it is useful to extend the research to include other compounds and other species of organisms.

The aim of this study was to investigate the influence of both natural and synthetic steroid hormones, such as estrogens (estrone, $\beta$-estadiol, 17- $\alpha$-ethinylestradiol, and estriol), progestogens (progesterone, 5 -pregnen-3 $\beta$-ol-20one, and levonorgestrel), and androgens (testosterone) on the growth of cyanobacteria. There is not enough information about the effect of steroid hormones on the growth of phytoplankton and the described results are the only reports showing the toxic effect of androgens and progestagens, and their common interaction of mixture on their cells. A number of physiological parameters, such as biomass and chlorophyll $a$ content, were assessed to define the chronic toxicity which would facilitate to understand how hormones affected cyanobacteria.

\section{Materials and methods}

\section{Culture conditions of Anabaena variabilis}

Anabaena variabilis ATCC-29413 was obtained from the Faculty of Biology, University of Lodz, Poland. Cyanobacteria were grown in sterilized glass Erlenmeyer flasks with vented closures to enhance gas exchange during incubation and shaking. The cultivation and experiments were performed in the mineral medium BG-11 (Rippka et al. 1979). The pH of the medium was adjusted to $7.64 \pm 0.02$ with $1 \mathrm{M} \mathrm{HCl}$ and/or $\mathrm{NaOH}$. In order to provide optimal growth conditions, the cultures were carried out in a phytotron chamber in the photoperiod 
in the light/dark cycle $12 / 12 \mathrm{~h}$, at temperature $23 / 20{ }^{\circ} \mathrm{C}$ (day/ night) with constant humidity of $30 \%$, and kept on rotator shaker (100 rpm). Cultures were grown under continuous illumination of $60 \mu \mathrm{mol}$ photons $\mathrm{m}^{-2} \mathrm{~s}^{-1}$. The cyanobacteria were grown in these conditions for several months before exposure. For the experiments, $100 \mathrm{~mL}$ of the liquid BG-11 medium containing A. variabilis cells was distributed to several $250-\mathrm{mL}$ Erlenmeyer flasks. The density of the culture before starting the experiment was $4 \times 10^{5}$ cells $\mathrm{mL}^{-1}$.

\section{Exposure of Anabaena variabilis to steroid hormones}

The A. variabilis colonies were cultured in the presence of the following single steroid hormones: estrone (E1), 17ß-estadiol (E2), 17- $\alpha$-ethinylestradiol (EE2), estriol (E3), progesterone (PRO), 5-pregnen-3 $\beta$-ol-20-one (PRE), levonorgestrel (LG), testosterone (TST). The cyanobacterium cultures also were exposed to mixed at equal proportion hormones, such as all of the examined hormones E1:E2:E3:EE2:PRO:PRE:TST:LG (1:1:1:1:1:1:1:1) (MIX1); the most toxic estrogens, progestogens, and androgens EE2:PRO:TST (1:1:1) (MIX2); and also the most toxic and showing no significant effects hormones PRO:E1:E3:LG (1:1:1:1) (MIX3) (Sigma, USA). The MIX1, MIX2, and MIX3 were prepared with $1 / 8,1 / 3$, and $1 / 4$ of each hormone $\left(\mathrm{mg} \mathrm{mL}^{-1}\right)$, respectively, to obtain the same final concentration tested for individual steroid hormones. The control samples were cultured in the same medium and in the same conditions, but without the presence of steroid hormones. Range finding assays were performed prior to final definitive tests in order to determine the concentrations in which effects are likely to occur. Each tested compound was first dissolved in methanol and then the dissolved form was added to $100 \mathrm{~mL}$ of cyanobacterium culture at the nominal concentrations $0.1,1,10,25,50,75$, and $100 \mathrm{mg} \mathrm{L}^{-1}$. The same amount of methanol was added to the control sample. The number of cells, biomass, and chlorophyll $a$ content were monitored in the cells of $A$. variabilis after 1, 2, 3, 7, 8, 10, 13, and 14 days of exposure to the analyzed chemical compounds and in control samples cultured in the same conditions.

\section{Measuring the growth of Anabaena variabilis}

The growth of the A. variabilis was assessed by counting the number of cells and determining biomass and chlorophyll $a$. The cyanobacterium cells were determined using a FuchsRosenthal hemocytometer, with an Olympus CX-41 (× 600) microscope equipped with an Olympus UC30 camera. In order to determine the biomass, $10 \mathrm{~mL}$ of the culture was filtered on the previously dried and weighed $47 \mathrm{~mm}$ diameter $3 \mu \mathrm{m}$ pore size nylon membrane filters (Yeti), and then dried for $1 \mathrm{~h}$ at $105{ }^{\circ} \mathrm{C}$ and weighed again. The concentration of chlorophyll $a$ was determined using an AlgaChek Ultra fluorometer (Modern Water, UK).

\section{Statistics}

The $\mathrm{EC}_{50}$ values (concentrations that cause a $50 \%$ growth inhibition) and the dose-response equation for A. variabilis were determined via dose-response curves prepared using Microsoft Excel (Microsoft Corporation, USA). EC E0 $_{50}$ values were calculated using linear regression analysis of transformed hormones concentration as natural logarithm data versus percent of inhibition.

The obtained results were statistically evaluated. Each treatment was repeated at least three times. The results are reported as the average of three parallel determinations of the mixture of three replicated samples. The Q-Dixon test was carried out and then the obtained values were averaged. The Q-Dixon test can be used for identification and rejection of outliers (Dixon 1953). Standard deviations (SD) were calculated in order to determine the accuracy and precision of the methods used. Regressions and confidence limit calculations were made using Statistica (StatSoft) software. Differences were considered significant for $P<0.05$.

\section{Results}

\section{The influence of single steroid hormones on the growth of Anabaena variabilis}

The chronic toxic effect of the eight single steroid hormones on A. variabilis was determined (Table 1). Figures 1 and 2 show changes in the algal biomass in the form of dry weight and chlorophyll $a$ content after exposure to the tested chemicals. Based on the obtained results, it can be observed that some of the hormones have a strongly inhibitory effect on the A. variabilis (Supplementary Table S1).

From among hormones tested individually, the strongest toxic effect was observed under the influence of progesterone, which produced a significant reduction in the number of cells, biomass, chlorophyll $a$, and $\mathrm{EC}_{50}$ values. This progestogen led to cyanobacterial cell death at 75 and $100 \mathrm{mg} \mathrm{L}^{-1}$ on the 13 th day of incubation. The remaining concentrations of progesterone inhibit the growth of $A$. variabilis from day 2 of the test. 17- $\alpha$-Ethinylestradiol also has a strong toxic effect and inhibits the growth of the cyanobacteria from day 2 of exposure, except for the lowest concentrations $\left(0.1\right.$ and $\left.1 \mathrm{mg} \mathrm{L}^{-1}\right)$ which do not significantly affect the growth of $A$. variabilis. Testosterone and 5-pregnen-3 $\beta$-ol-20-one significantly inhibited the growth of cyanobacteria from the 7 th day of exposure to these compounds. During the first 3 days, no significant differences were observed in the presence of these hormones compared to the control sample. However, after day 7 , a significant inhibition of cyanobacterial growth at higher concentrations (50-100 $\mathrm{mg} \mathrm{L}^{-1}$ ) was observed. Meanwhile, in the case of $\beta$-estadiol, during the first 3 days of exposure, the 
growth of A. variabilis was stimulated and during the next days, the growth was inhibited by $10-100 \mathrm{mg} \mathrm{L}^{-1}$ of this estrogen. The weakest effects on the A. variabilis were shown by estrone, estriol, and levonorgestrel which, in the studied range of concentrations, do not significantly affect the growth. Table 1 shows the $\mathrm{EC}_{50}$ values for the steroid hormones tested with a $95 \%$ confidence interval. Based on the determined $\mathrm{EC}_{50}$ values, among all of the tested endocrine compounds, the strongest toxic effects on A. variabilis cells were exerted by progesterone and 17- $\alpha$-ethinylestradiol (14 days $\mathrm{EC}_{50}$, 48.59 and $82.95 \mathrm{mg} \mathrm{L}^{-1}$ ). A moderately toxic effect was observed for 5 -pregnen-3 $\beta$-ol-20-one, testosterone and $\beta$ estadiol, for which the $\mathrm{EC}_{50}$ after 14 days of exposure were 283.50, 336.68, and $437.82 \mathrm{mg} \mathrm{L}^{-1}$, respectively. In contrast, estrone, estriol, and levonorgestrel showed a slightly toxic effect on A. variabilis. Based on the number of cells, chlorophyll $a$ and biomass determined $\mathrm{EC}_{50}$ values; the toxic effects of endocrine compounds can be ranked as follows: PRO $>$ EE2 $>>$ PRE $>$ TST $>$ E2 $>$ E3 $>$ LG $>$ E1 .

\section{The influence of mixed steroid hormones on the growth of Anabaena variabilis}

The number of cells, chlorophyll $a$, and biomass of $A$. variabilis exposed to mixture hormones are shown in Supplementary Table S1 and in Figs. 3 and 4. $\mathrm{EC}_{50}$ values are listed in Table 1. In the case of mixed steroid hormones MIX1, a highly toxic effect on A. variabilis was observed. The obtained results show that the hormone mixture lead to death of the cyanobacterium culture at concentrations of 75 and $100 \mathrm{mg} \mathrm{L}^{-1}$ already on the 7th day of exposure. Under the influence of 10 and $25 \mathrm{mg} \mathrm{L}^{-1}$, the growth of the cyanobacteria is inhibited, while for the remaining concentrations, no significant differences were observed compared to the control sample. MIX2 leads also to death of A. variabilis cultures. The mixed estrogen, progestin, and androgen shows the most toxic effect on A. variabilis. Total death of cells is already achieved on the 3 rd day of exposure at concentrations of 75 and $100 \mathrm{mg} \mathrm{L}^{-1}$. The remaining concentrations significantly inhibit growth. On the other hand, MIX3 shows a significantly weaker effect on cyanobacterial cells compared to the other mixed steroid hormones. As can be seen in Table 1, the $\mathrm{EC}_{50}$ values for the tested steroid hormone mixtures were 45.16, 37.00, and $89.46 \mathrm{mg} \mathrm{L}^{-1}$ for MIX1, MIX2, and MIX3, respectively.

\section{Discussion}

As is well known, steroid hormones negatively affect many organisms living in aquatic ecosystems, including species of fish, amphibians, mollusks, and zooplankton (Czarny et al. 2017). Less is known about the effect of these 
Fig. 1 The changes in the biomass in the form of dry weight $\left[\mathrm{mg} \mathrm{L}^{-1}\right]$ of Anabaena variabilis after exposure to different concentrations $\left(0.1-100 \mathrm{mg} \mathrm{L}^{-1}\right)$ of single (a estrone, b 17ßestadiol, c estriol, d 17- $\alpha$ ethinylestradiol, e progesterone, f 5-pregnen-3 $\beta$-ol 20-one, g levonorgestrel, $\mathbf{h}$ testosterone) steroid hormones. The error bars represent standard deviation $(P<0.05, n=3)$

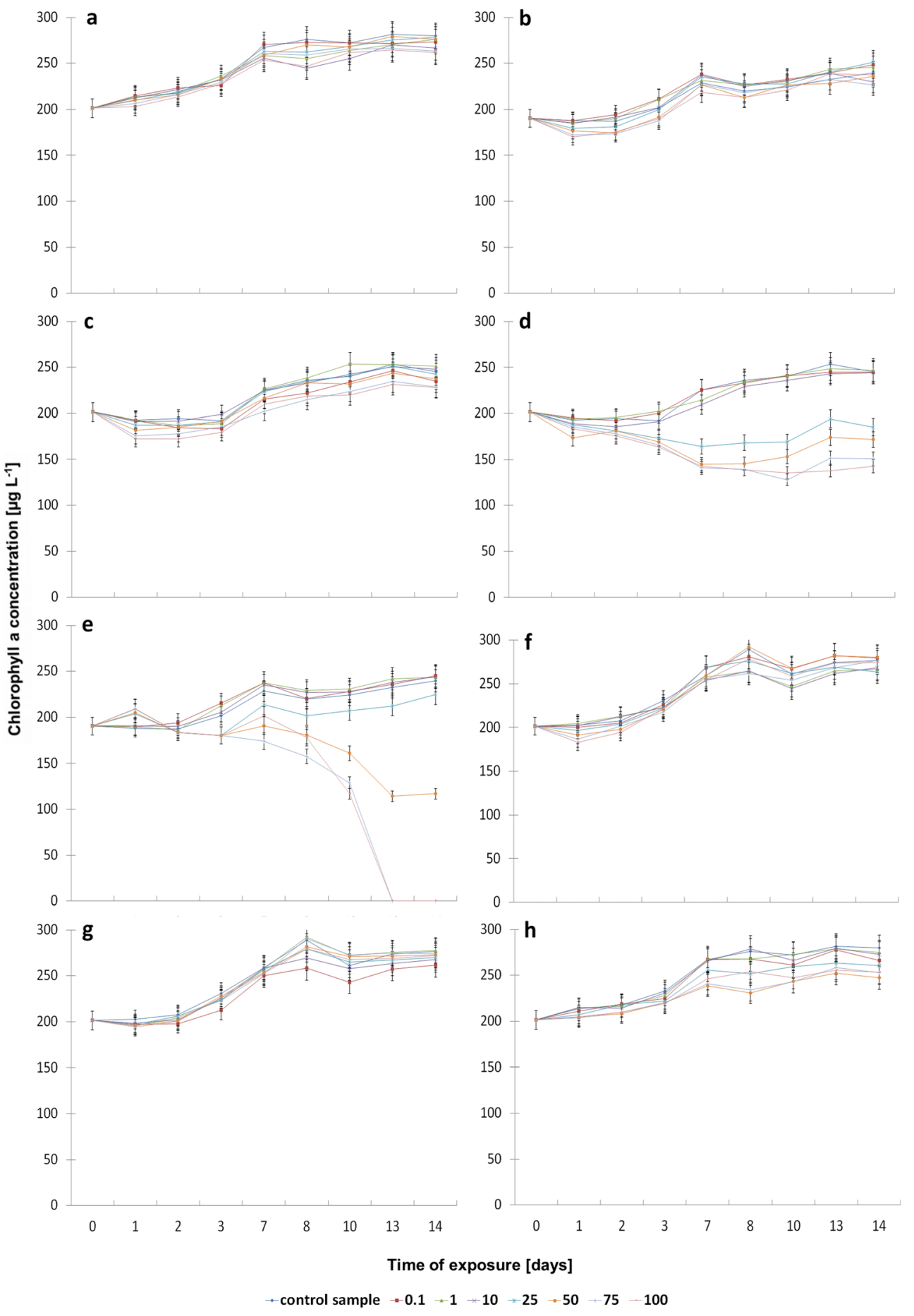

compounds on the development of phytoplankton and the only information concerns the effect of estrogen. Salomao et al. (2014) examined the effect of natural steroid hormones such as estrone, $\beta$-estadiol, and synthetic 17- $\alpha$ ethinylestradiol in the green algae Desmodesmus subspicatus and Pseudokirchneriella subcapitata and also noted that EE2 and E2 show more toxic effects on cells than E1. The cultures of both green algal species were most sensitive to $17-\alpha$ ethinylestradiol, for which the obtained $\mathrm{EC}_{50}$ values were
0.73 and $0.80 \mathrm{mg} \mathrm{L}^{-1}$, respectively. They also showed that $P$. subcapitata was more sensitive to the tested estrogens than D. subspicatus (Salomao et al. 2014). Pocock and Falk (2014) also noted the negative effect of 17- $\alpha$-ethinylestradiol on the growth and photosynthesis of the green alga Chlamydomonas reinhardtii at a concentration of $10 \mathrm{pM}$. Comparing their results, it can be concluded that these phytoplankton species are much more sensitive to the action of estrogens than the tested A. variabilis. The results obtained by Liu et al. (2010) 


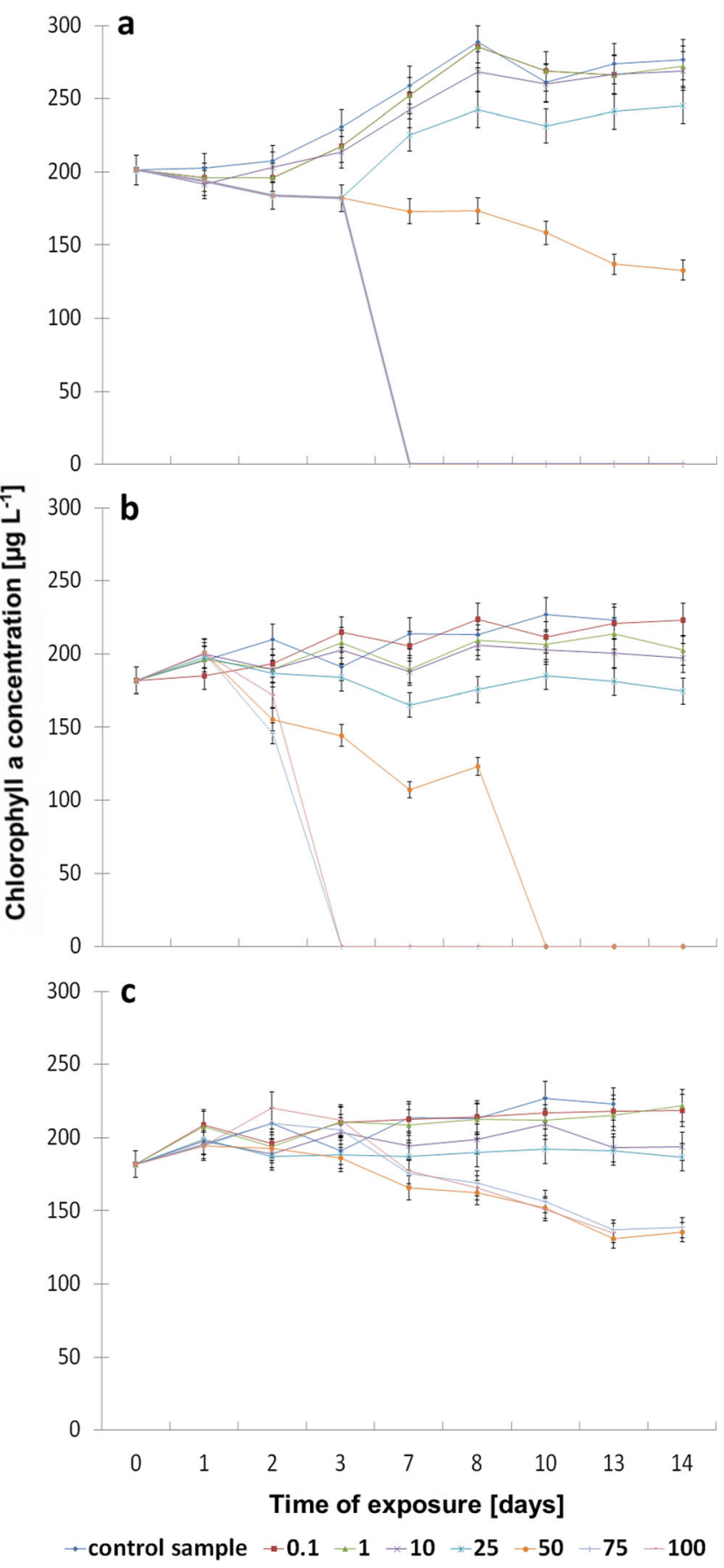

Fig. 2 Chlorophyll $a$ concentration $\left[\mu \mathrm{g} \mathrm{L}^{-1}\right]$ of Anabaena variabilis after exposure to different concentrations $\left(0.1-100 \mathrm{mg} \mathrm{L}^{-1}\right)$ of single (a estrone, b 17ß-estadiol, c estriol, d 17- $\alpha$-ethinylestradiol, e progesterone, $\mathbf{f} 5$-pregnen-3 $\beta$-ol 20 -one, $\mathbf{g}$ levonorgestrel, $\mathbf{h}$ testosterone) steroid hormones. The error bars represent standard deviation $(P<0.05$, $n=3$ )

confirm the toxic effect of estrogens on phytoplankton cells. Their toxicity tests showed that incubation in the presence of $17-\alpha$-ethinylestradiol and $\beta$-estadiol led to growth inhibition of the diatom Navicula incerta and the determined $\mathrm{EC}_{50}$ values were 3.21 and $>10 \mathrm{mg} \mathrm{L}^{-1}$, respectively. This confirms that the occurrence of synthetic EE2 in the aquatic environment has a more profound effect on the growth of algae than natural estrogens. A similar tendency of hormones is observed not only for phytoplankton cells, but also for other aquatic organisms. Lange et al. (2012) studied the effect of estrogens on the feminization of wild freshwater fish, and their capability for disruption of the endocrine system increased in the order: EE2 $>$ E2 $>$ E3 $>$ E1. In the literature, there are many reports on the influence of progestins and androgens on the endocrine system of fish. However, the toxicity of progestagens and androgens and their interaction in a mixture on phytoplankton growth has not been studied yet, and the presented results are the only reports on this topic. According to many authors, a large number of phytoplankton strains are able to convert pharmaceutical pollutants in surface water and wastewater into useful metabolites (Gentili and Fick 2017; Ojoghoro et al. 2017; Wang et al. 2017). Safiarian et al. (2012) studied the bioconversion efficiency of progesterone in the range of 50 to $400 \mathrm{mg} \mathrm{L}^{-1}$ by cyanobacterium Microchaete tenera. They show that the optimum concentration of progestagen, which gave maximum bioconversion efficiency, was $250 \mathrm{mg} \mathrm{L}^{-1}$ and higher concentrations (400 $\mathrm{mg} \mathrm{L}^{-1}$ ) inhibited the bioconversion completely. Peng et al. (2015) observed that $1.6 \mu \mathrm{M}$ progesterone and levonorgestrel did not significantly influence the growth of Scenedesmus obliquus and Chlorella pyrenoidosa. The results obtained by Wang et al. (2013) suggested that microalga species were tolerant to estrogens (E2, EE2), but the effects were species specific, and the way each species combats the oxidative stress posed by hormones was different. The phytoplankton transformation of hormones could have environmental implications in their fate and potential implementation in wastewater treatment (Escapa et al. 2017). All of these results highlight the importance of species selection in the application of phytoplankton for wastewater treatment. In this study, in most cases, $\mathrm{EC}_{50}$ values decrease with time, which suggested a time response attenuation effect, as previously observed for $P$. subcapitata and D. subspicatus exposed to E1, E2, and EE2 (Salomao et al. 2014).

In the aquatic environment, organisms such as phytoplankton are exposed to hormones, which usually do not occur alone, but in a mixture (Lei et al. 2009; Ben Sghaier et al. 2017). An additive effect of mixed compounds is often assumed, so toxicity of the mixture is similar to the sum of toxicities of individual components. However, there are cases where toxicity is significantly higher than the additive toxicity, and then potentiation of toxicity (less than additive effect) can be observed. In the present study, the $\mathrm{EC}_{50}$ values for all tested mixed steroid hormones decrease with time, suggesting that their toxicity increases. Comparing them with values for single steroid hormones, it can be seen that the sum of toxicities of individual components is much higher than the toxicity of the mixed hormones. Increased toxicity against $A$. variabilis 
Fig. 3 The changes in the biomass in the form of dry weight $\left[\mathrm{mg} \mathrm{L}^{-1}\right]$ of Anabaena variabilis after exposure to different concentrations $\left(0.1-100 \mathrm{mg} \mathrm{L}^{-1}\right)$ of mixed (a MIX1, b MIX2, c MIX3) steroid hormones. The error bars represent standard deviation $(P<0.05, n=3)$

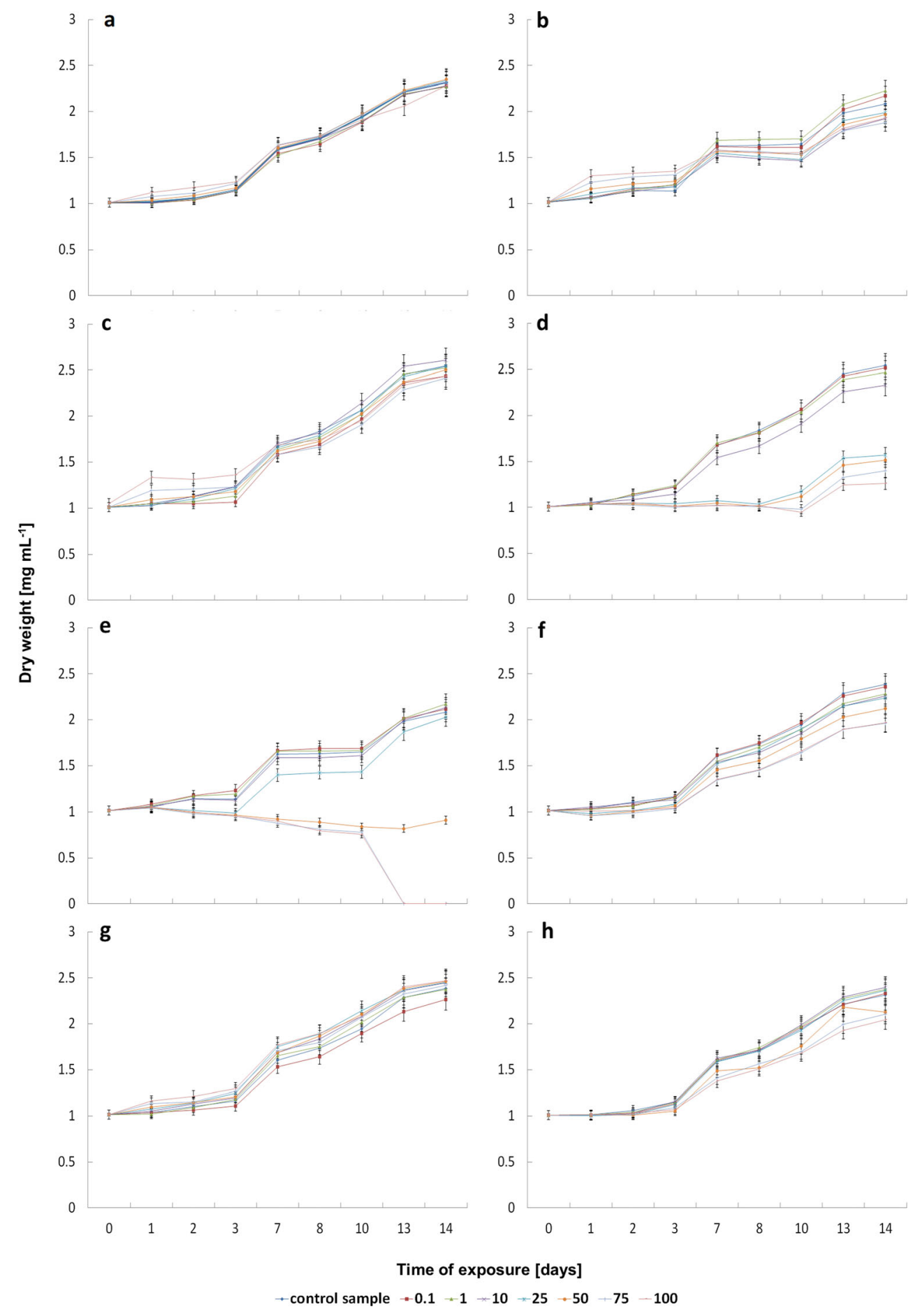

due to the presence of mixed hormones suggests that their action is potentiated. This is a particularly dangerous phenomenon because in the aquatic environment, hormones were present in mixtures, so their effect on phytoplankton can lead to inhibition of their growth. As a consequence, it may lead to changes in the structure of their biocenosis, creating a serious threat to entire aquatic ecosystems. It can be noticed that the composition of hormones in their mixtures has a decisive effect on their toxicity. The smallest value of $\mathrm{EC}_{50}$ is shown by MIX2. These high toxicities result from the presence of three hormones (EE2, PRO, TST), which caused the strongest inhibitory effect on the growth of $A$. variabilis. A highly toxic effect, although weaker than in the case of MIX2, was shown by MIX1. It consists of all of the tested hormones and the lowest toxicity is associated with the effect of diluting the most active compounds. The weakest effect is shown after 
a

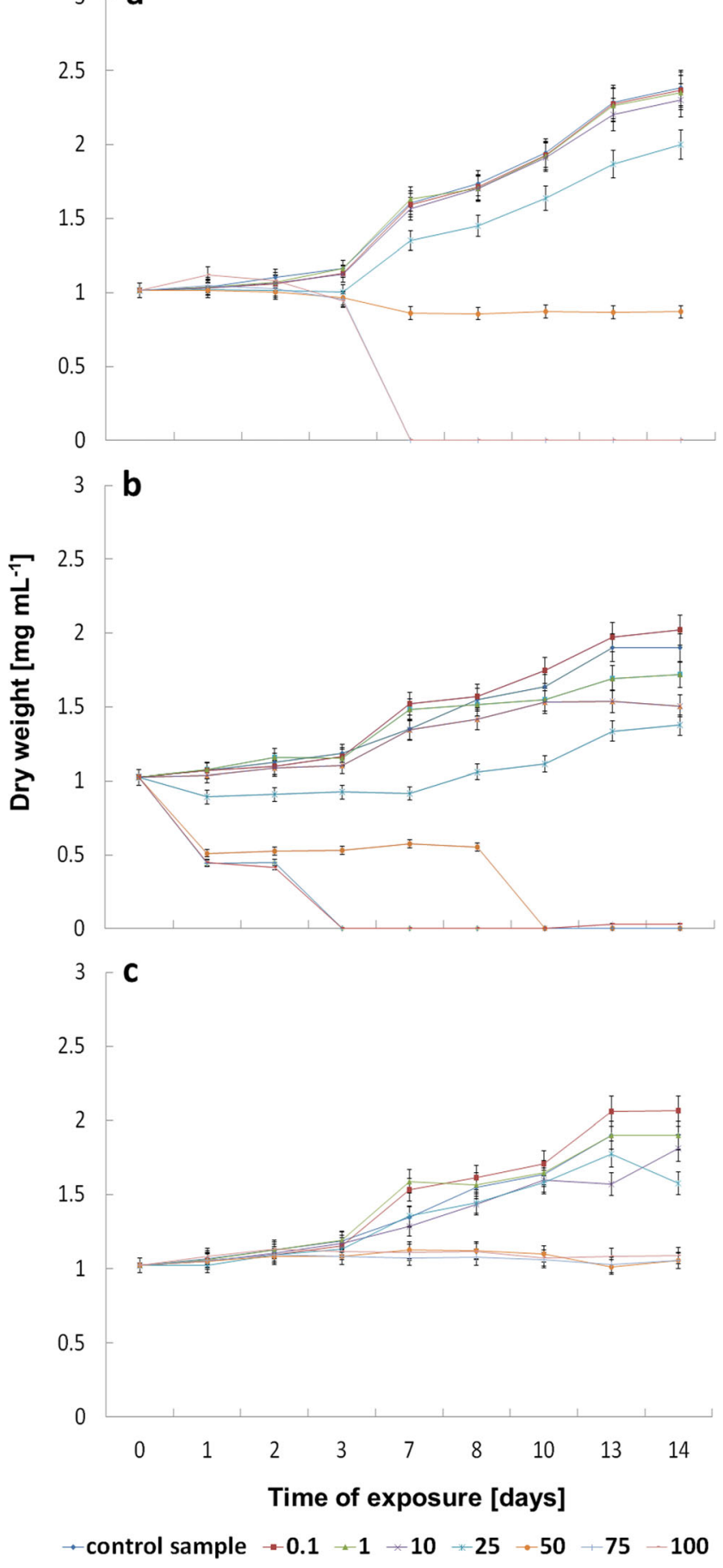

Fig. 4 Chlorophyll a concentration $\left[\mu \mathrm{g} \mathrm{L}^{-1}\right]$ of Anabaena variabilis after exposure to different concentrations $\left(0.1-100 \mathrm{mg} \mathrm{L}^{-1}\right)$ of mixed (a MIX1, b MIX2, c MIX3) steroid hormones. The error bars represent standard deviation $(P<0.05, n=3)$

incubation of MIX3. It is caused by the presence of three steroid hormones (E1, E3, and LG), which only slightly affect the growth and only one (PRO), which has a toxic effect on $A$. variabilis. The only reports on the impact of mixed hormones on phytoplankton cells can be found in Salomao et al. (2014) who studied the effect of E1:E2:EE2 mixed in equal proportions (1:1:1) on the green alga $D$. subspicatus. After $96 \mathrm{~h}$ of the test, the $\mathrm{EC}_{50}$ values for single estrogens were $7.25,1.07$, and $0.73 \mathrm{mg} \mathrm{L}^{-1}$, respectively, while for the hormone mixture, this value was $4.94 \mathrm{mg} \mathrm{L}^{-1}$. The obtained toxic effect is higher than the total value of individual estrogens, which suggests that also in the case of this green algae, potentiation of toxicity by the presence of estrogens was observed (Salomao et al. 2014).

The mechanisms of action of steroid hormones on $A$. variabilis cells are not well understood yet. It is known that EDCs disturb the hormonal balance and negatively affect the functioning of the endocrine system of many aquatic organisms (Abdel-Moneim et al. 2015; Hu et al. 2017). However, phytoplankton cells are organisms that do not have the endocrine system, which is why their mechanism of action is different. It can be assumed that due to their lipophilic nature (Table 1), they easily penetrate the phytoplankton cell membranes and bioaccumulate (Silva et al. 2012; Blewett et al. 2014). Perron and Juneau (2011a) showed that endocrinedisrupting substances affect photosynthesis activity and have a negative effect on PSII energy fluxes. In addition, it was observed that cyanobacteria were much more sensitive to these compounds than the green algae, suggesting that the prokaryotic structure of these organisms is responsible for their particular sensitivity. Balina et al. (2015) in their studies also confirmed the effect of hormones on the alga photosystem. In addition, they showed that increased concentrations of EE2 lead to damage and inhibition of cell division of microalgae and affect the ability of phytoplankton cells to grow.

\section{Conclusions}

The presented studies show that single and mixed steroid hormones may inhibit the growth of the cyanobacterium $A$. variabilis. From among tested hormones, progesterone showed a highly toxic effect. Incubation in the presence of these progestogens leads to the cell death of the cultures during the 13th day of the test at concentrations of 75 and $100 \mathrm{mg} \mathrm{L}^{-1}$. Similar results were obtained under the incubation with 17- $\alpha$-ethinylestradiol, and the growth of $A$. variabilis was more strongly inhibited than in the case of $\beta$ estadiol, 5-pregnen-3 $\beta$-ol-20-one, and testosterone. Estrone, estriol, and levonorgestrel have no significant effect on the growth of the cyanobacterium cultures. In summary, based on the $\mathrm{EC}_{50}$ values, single hormones toxicity increases in the order: $\mathrm{PRO}>\mathrm{EE} 2>>\mathrm{PRE}>\mathrm{TST}>\mathrm{E} 2>\mathrm{E} 3>\mathrm{LG}>\mathrm{E} 1$. The strongest toxic effect on the studied cyanobacteria is shown by mixed steroid hormones and leads to the potentiation of the toxicity. MIX2 and MIX1 were more toxic than MIX3, and the toxic effect on $A$. variabilis cultures depends on the composition of the mixture. The $\mathrm{EC}_{50}$ values for all tested steroid hormones decrease with time, suggesting that their toxicity 
increases. An increase in the consumption of pharmaceuticals causes an inevitable increase in the contamination of the aquatic environment with compounds such as steroid hormones. In the future, the concentrations of these endocrine active compounds may increase enough to inhibit phytoplankton growth and disrupt the balance of entire aquatic ecosystems. Due to the small number of publications on the effect of steroid hormones on phytoplankton, their effects are not fully understood. In addition, studies show that the presence of a mixture of these contaminants in the aquatic environment may cause a much stronger effect on living organisms and in the case of steroid hormones there is a potentiation of toxicity. Therefore, further research on other endocrine and phytoplankton compounds is needed to fully understand how steroid hormones affect these aquatic organisms, to provide a more comprehensive view of the ecological risk assessment. Further study should be conducted on the bioaccumulation, food chain transport, and distribution of hormones in organisms of different trophic levels in the aquatic environment.

Open Access This article is distributed under the terms of the Creative Commons Attribution 4.0 International License (http:// creativecommons.org/licenses/by/4.0/), which permits unrestricted use, distribution, and reproduction in any medium, provided you give appropriate credit to the original author(s) and the source, provide a link to the Creative Commons license, and indicate if changes were made.

\section{References}

Abdel-Moneim A, Mahapatra CT, Hatef A, Sepulveda MS (2015) Ovarian structure protein 1: a sensitive molecular biomarker of gonadal intersex in female Japanese Medaka after androgen exposure. Environ Toxicol Chem 34:2087-2094

Ahmed NB, Masse S, Laurent G, Piquemal JY, Yepremian C, Brayner R, Coradin T (2018) Optical microalgal biosensors for aqueous contaminants using organically doped silica as cellular hosts. Anal Bioanal Chem 410:1205-1216

Aris AZ, Shamsuddin AS, Praveena SM (2014) Occurrence of $17 \alpha-$ ethynylestradiol (EE2) in the environment and effect on exposed biota: a review. Environ Int 69:104-119

Balina K, Balode M, Muzikante L, Blumberga D (2015) Impact of synthetic hormone $17 \alpha$-ethinylestradiol on growth of microalgae Desmodesmus communis. Agron Res 13:445-454

Ben Fredj S, Novakoski RT, Tizaoui C, Monser L (2017) Two-phase ozonation for the removal of estrone, $17 \beta$-estradiol and $17 \alpha$-ethinylestradiol in water using ozone-loaded decamethylcyclopentasiloxane. Ozone Sci Eng 39:343-356

Ben Sghaier R et al (2017) Simultaneous detection of 13 endocrine disrupting chemicals in water by a combination of SPE-BSTFA derivatization and GC-MS in transboundary rivers (FranceBelgium). Water Air Soil Pollut 228:2-14

Blewett TA, Chow TL, MacLatchy DL, Wood CM (2014) A species comparison of 17- $\alpha$-ethynylestradiol uptake and tissue-specific distribution in six teleost fish. Comp Biochem Physiol C 161:33-40

Brulport A, Le Corre L, Chagnon MC (2017) Chronic exposure of 2,3,7, 8-tetrachlorodibenzo-p-dioxin (TCDD) induces an obesogenic effect in C57BL/6J mice fed a high fat diet. Toxicology 390:43-52
Czarny K, Szczukocki D, Krawczyk B, Zielinski M, Miekos E, GadzalaKopciuch R (2017) The impact of estrogens on aquatic organisms and methods for their determination. Crit Rev Environ Sci Technol 47:909-963

Daughton CG, Ternes TA (1999) Pharmaceuticals and personal care products in the environment: agents of subtle change? Environ Health Perspect 107:907-938

DeQuattro ZA, Peissig EJ, Antkiewicz DS, Lundgren EJ, Hedman CJ, Hemming JD, Barry TP (2012) Effects of progesterone on reproduction and embryonic development in the fathead minnow (Pimephales promelas). Environ Toxicol Chem 31:851-856

DeWitt JC, Patisaul HB (2018) Endocrine disruptors and the developing immune system. Curr Opin Toxicol 10:31-36

Diamanti-Kandarakis E, Bourguignon JP, Giudice LC, Hauser R, Prins GS, Soto AM, Zoeller RT, Gore AC (2009) Endocrine-disrupting chemicals: an Endocrine Society scientific statement. Endocr Rev 30:293-342

Dionisio KL, Frame AM, Goldsmith MR, Wambaugh JF, Liddell A, Cathey T, Smith D, Vail J, Ernstoff AS, Fantke P, Jolliet O, Judson RS (2015) Exploring consumer exposure pathways and patterns of use for chemicals in the environment. Toxicol Rep 2:228-237

Dixon WJ (1953) Processing data for outliers. Biometrics 9:74-89

do Nascimento MTL, Santos ADO, Felix LC, Gomes G, de Oliveira E Sá M, da Cunha DL, Vieira N, Hauser-Davis RA, Baptista Neto JA, Bila DM (2018) Determination of water quality, toxicity and estrogenic activity in a nearshore marine environment in Rio de Janeiro, Southeastern Brazil. Ecotoxicol Environ Saf 149:197-202

Dong X, Zhang Z, Meng S, Pan C, Yang M, Wu X, Yang L, Xu H (2018) Parental exposure to bisphenol A and its analogs influences zebrafish offspring immunity. Sci Total Environ 610:291-297

Erickson BE (2017) How many chemicals are in use today? C\&EN 95: 23-24

Escapa C, Coimbra RN, Paniagua S, García AI, Otero M (2017) Comparison of the culture and harvesting of Chlorella vulgaris and Tetradesmus obliquus for the removal of pharmaceuticals from water. J Appl Phycol 29:1179-1193

Gao J, Liu S, Zhang Y, Yang Y, Yuan C, Chen S, Wang Z (2015) Effects of 17 alpha-methyltestosterone on transcriptome, gonadal histology and sex steroid hormones in rare minnow Gobiocypris rarus. Comp Biochem Physiol D 15:20-27

Gentili FG, Fick J (2017) Algal cultivation in urban wastewater: an efficient way to reduce pharmaceutical pollutants. J Appl Phycol 29: 255-262

Hanselman TA, Graetz DA, Wilkie AC (2003) Manure-borne estrogens as potential environmental contaminants: a review. Environ Sci Technol 37:5471-5478

He J, Peng T, Yang X, Liu H (2018) Development of QSAR models for predicting the binding affinity of endocrine disrupting chemicals to eight fish estrogen receptor. Ecotoxicol Environ Saf 148:211-219

Hu SQ, Zhang HC, Shen GX, Yuan ZJ, Xu T, Ji R (2017) Effects of 17 estradiol and $17 \alpha$-ethinylestradiol on the embryonic development of the clearhead icefish (Protosalanx hyalocranius). Chemosphere 176:18-24

Kabzinski AKM, Szczukocki D, Macioszek B, Juszczak R, Grabowska H, Cyran J, Dziegieć J, Zawadzka A, Szczęsna-Kulesza S (2007) Experiments with application of chlorine dioxide and ozone for removing of cyanobacterial toxins from Sulejow-Lodz system, Ecol Chem Eng. 14:339-358 (in Polish)

Kida M, Ziembowicz S, Koszelnik P (2018) Removal of organochlorine pesticides (OCPs) from aqueous solutions using hydrogen peroxide, ultrasonic waves, and a hybrid process. Sep Purif Technol 192:457464

Krishnan K, Brodeur J (1994) Toxic interactions among environmentalpollutants - corroborating laboratory observations with human-experience. Environ Health Perspect 102:11-17 
Lange A, Katsu Y, Miyagawa S, Ogino Y, Urushitani H, Kobayashi T, Hirai T, Shears JA, Nagae M, Yamamoto J, Ohnishi Y, Oka T, Tatarazako N, Ohta Y, Tyler CR, Iguchi T (2012) Comparative responsiveness to natural and synthetic estrogens of fish species commonly used in the laboratory and field monitoring. Aquat Toxicol 109:250-258

Leet JK, Gall HE, Sepulveda MS (2011) A review of studies on androgen and estrogen exposure in fish early life stages: effects on gene and hormonal control of sexual differentiation. J Appl Toxicol 31:379398

Lei BL, Huang SB, Zhou YQ, Wang DH, Wang ZJ (2009) Levels of six estrogens in water and sediment from three rivers in Tianjin area, China. Chemosphere 76:36-42

Lei B, Wen Y, Wang X, Zha J, Li W, Wang Z, Sun Y, Kang J, Wang Y (2013) Effects of estrone on the early life stages and expression of vitellogenin and estrogen receptor genes of Japanese Medaka (Oryzias latipes). Chemosphere 93:1104-1110

Li J, Cheng W, Xu L, Jiao Y, Baig S, Chen H (2016) Occurrence and removal of antibiotics and the corresponding resistance genes in wastewater treatment plants: effluents' influence to downstream water environment. Environ Sci Pollut Res 23:6826-6835

Liang YQ, Huang GY, Liu SS, Zhao JL, Yang YY, Chen XW, Tian F, Jiang YX, Ying GG (2015) Long-term exposure to environmentally relevant concentrations of progesterone and norgestrel affects sex differentiation in zebrafish (Danio rerio). Aquat Toxicol 160:172179

Liu Y, Guan Y, Gao Q, Tam NF, Zhu W (2010) Cellular responses, biodegradation and bioaccumulation of endocrine disrupting chemicals in marine diatom Navicula incerta. Chemosphere 80: 592-599

Macioszek B, Szczukocki D, Dziegiec J (2010) Inhibition of the growth of Microcrystis aureginosa by phenolic allelochemicals from aquatic macrophytes or decomposed barley straw. In: Dudzińska MR, Pawłowski A, Pawłowski L (eds) Environmental engineering III. Taylor \& Francis, London, pp 485-489

Martinez-Alcala I, Pellicer-Martinez F, Fernandez-Lopez C (2018) Pharmaceutical grey water footprint: accounting, influence of wastewater treatment plants and implications of the reuse. Water Res 135: 278-287

Nadal A, Fuentes E, Ripolla C, Villar-Pazosa S, Castellano-Muñoza M, Soriano S, Martinez-Pinna J, Quesada I, Alonso-Magdalena P (2018) Extranuclear-initiated estrogenic actions of endocrine disrupting chemicals: is there toxicology beyond Paracelsus? J Steroid Biochem Mol Biol 176:16-22

Ojoghoro JO, Chaudhary AJ, Campo P, Sumpter JP, Scrimshaw MD (2017) Progesterone potentially degrades to potent androgens in surface waters. Sci Total Environ 579:1876-1884

Patisaul HB, Jefferson W (2010) The pros and cons of phytoestrogens. Front Neuroendocrinol 31:400-419

Peng F-Q, Ying G-G, Yang B, Liu S, Lai H-J, Liu Y-S, Chen Z-F, Zhou G-J (2015) Biotransformation of progesterone and norgestrel by two freshwater microalgae (Scenedesmus obliquus and Chlorella pyrenoidosa): transformation kinetics and products identification. Chemosphere 95:581-588
Perron MC, Juneau P (2011a) Effect of endocrine disrupters on photosystem II energy fluxes of green algae and cyanobacteria. Environ Res 111:520-529

Phuge SK, Gramapurohit NP (2015) Sex hormones alter sex ratios in the Indian skipper frog, Euphlyctis cyanophlyctis: determining sensitive stages for gonadal sex reversal. Gen Comp Endocrinol 220:70-77

Piprek RP, Pecio A, Kubiak JZ, Szymura JM (2012) Differential effects of testosterone and $17 \beta$-estradiol on gonadal development in five anuran species. Reproduction 144:257-267

Pocock T, Falk S (2014) Negative impact on growth and photosynthesis in the green alga Chlamydomonas reinhardtii in the presence of the estrogen $17 \alpha$-ethynylestradiol. PLoS One 9:e109289

Rippka R, Deruelles J, Waterbury JB, Herdman M, Stranier RY (1979) Genetic assignments, strain histories and properties of pure cultures of cyanobacteria. J Gen Microbiol 11:1-61

Safiarian MS, Faramarzi MA, Amini M, Soltani N, Tabatabaei-Sameni M, Hasan-Beikdashti M (2012) Microalgal transformation of progesterone by the terrestrial-isolated cyanobacterium Microchaete tenera. J Appl Phycol 24:777-781

Salomao AL, Soroldoni S, Marques M, Hogland W, Bila DM (2014) Effects of single and mixed estrogens on single and combined cultures of D. subspicatus and P. subcapitata. Bull Environ Contam Toxicol 93:215-221

Sangster JL, Ali JM, Snow DD, Kolok AS, Bartelt-Hunt SL (2016) Bioavailability and fate of sediment-associated progesterone in aquatic systems. Environ Sci Technol 50:4027-4036

Silva CP, Otero M, Esteves V (2012) Processes for the elimination of estrogenic steroid hormones from water: a review. Environ Pollut $165: 38-58$

Torres MA, Barros MP, Campos SC, Pinto E, Rajamani S, Sayre RT, Colepicolo P (2008) Biochemical biomarkers in algae and marine pollution: a review. Ecotoxicol Environ Saf 71:1-15

Volkova NA, Goltsev AN (2015) Cryopreservation effect on proliferation and differentiation potential of cultured chorion cells. Cryo Letters 36:25-29

Wang J, Zhu YD (2017) Occurrence and risk assessment of estrogenic compounds in the East Lake, China. Environ Toxicol Pharmacol 52: 69-76

Wang P, Wong MH, Tam NFY (2013) Antioxidant responses of two microalgae, Selenastrum capricornutum and Chlorella sp., to estradiol and ethinylestradiol. J Appl Phycol 25:891-903

Wang P, Wong Y-S, Tam NF-Y (2017) Green microalgae in removal and biotransformation of estradiol and ethinylestradiol. J Appl Phycol 29:263-273

Ying GG, Kookana RS, Ru YJ (2002) Occurrence and fate of hormone steroids in the environment. Environ Int 28:545-551

Zhang YY, Dong SJ, Wang HG, Tao S, Kiyama R (2016) Biological impact of environmental polycyclic aromatic hydrocarbons (ePAHs) as endocrine disruptors. Environ Pollut 213:809-824

Zhang M, Shi Y, Lu Y, Johnson AC, Sarvajayakesavalu S, Liu Z, Su C, Zhang Y, Juergens MD, Jin X (2017) The relative risk and its distribution of endocrine disrupting chemicals, pharmaceuticals and personal care products to freshwater organisms in the Bohai Rim, China. Sci Total Environ 590:633-642 